\title{
Teachers teaching life-cycle and academic productivity: a pilot study of one higher education institutions in northern mindanao
}

\author{
Elizabeth H. Remigoso ${ }^{\mathrm{a}}$, Dr. Renato L. Base ${ }^{\mathrm{b} *}$ \\ a abeth24@yahoo.com, ${ }^{b}$ renato.base@ustp.edu.ph \\ ${ }^{a}$ Camiguin Polytechnic State College, Mambajao, Camiguin, 9100 Mindanao, Philippines \\ ${ }^{b}$ University of Science and Technology of Southern Phillipines, Cagayan de oro City Campus 9000, Philippines
}

\begin{abstract}
The objective of the study was to demonstrate whether Huberman's teaching career cycle model can shed similar insights when used in Camiguin Polytechnic State College, whose context and setting is very different from the one used in the original study. In particular, the study attempted to find out whether academic productiveness was associated with the stages as indicated in Huberman's teaching career cycle model. A survey design was used with a 132 faculty and staff as respondents. The findings have shown that academic productiveness was significantly associated with the stages in the teaching career cycle model in the context and settings of Camiguin Polytechnic State College. On that note, the higher a faculty goes through the stages the more academically productive they are in which the highest odds is that of faculty in the serenity stage. Hence, the findings demonstrated that though this study was conducted in a setting and context very different from that of the original, indeed, academic productiveness was significantly associated with the Huberman teaching cycle model, which meant that for this particular setting and context, the Huberman model demonstrated its appeal and potential. On this basis, there is a need to take seriously the significance of the Huberman teaching career cycle model particularly for school administrator as they come up with decision and formulate policies and programs that have significant bearing to faculty's academic productiveness in the realm of research and development.
\end{abstract}

Keywords: teaching career cycle; academic productiveness; educational planning and management 


\section{Main text}

\section{Introduction}

\subsection{Rationale}

In Philippine context, reforms to enhance the performance of higher education institutions have been steadily proceeding. Underlying this reforms were to produce innovators, researcher's and knowledge producers in which currently the country has lagged behind vis-a-vis its ASEAN neighbors in producing researchers, innovators and solutions providers, which are needed and crucial to effectively function in a knowledge economy (Macha, Mackie, \& Magaziner, 2018).

Although Filipino experts have noted that the number of graduates from higher education programs has recently exceeded expectations, nonetheless, with regards to improvement in higher education performance particularly when it comes to knowledge production, one notable area was the slight increase in the number of higher education faculty holding graduate level degrees. The percentage of instructors with master's and doctoral degrees grew from 38.9 percent and 11.1 percent in 2010, to 40.3 and 12.6 percent in 2015. The number of Higher Education Institutions (HEIs), on the other hand, with accredited education programs, which is not mandatory in the Philippines, likewise increased by more than 40 percent between 2010 to 2017, while the pass rates of candidates sitting for professional licensing exams, a measure of academic productiveness, jumped from 33.9 to 58.6 percent between 2010 and 2015. Nevertheless, we are still behind with our ASEAN neighbor when it comes to knowledge economy which is related to academic productivity.

In an attempt to boost the country's research output, the government in 2017 also institutionalized the so-called "Balik (Returning) Scientist Program," an initiative that was first created in the 1970s to incentivize highly skilled Filipino researchers working abroad to return to the Philippines. Benefits provided through the program included research grants, free health insurance, and relocation allowances. Though this was a laudable effort on the part of the government, nevertheless, there is also a need to complement this program by way of improving the current academic productiveness specifically of teachers/professors in the higher education institutions. Presently, it cannot be denied that the current acute shortage of researches, as a measure of academic productiveness, is impinged by many factors that may hinder or may facilitate academic productivity. One such factor oftentimes overlooked is whether academic productivity has something to do with the teaching life-cycle of teachers at the tertiary level. 
It must be emphasized that studies of this kind is very significant since it will attempt to understand academic productiveness within the context of the teaching career cycle of teachers at the tertiary level, and if fully appreciated could provide evidence-based data that may complement the attempt of the Philippine government to boosts the country's research output. In other words, if insight can be gleaned on the dynamic relation between academic productiveness and the teaching career cycle of teachers in the higher education institutions, then appropriate policies and programs may be formulated that may serve as counterpart in the Philippine's government effort of boosting the country's research output.

Production of knowledge is crucial particularly for those in the academe. Hence, there is a need to further understand the changes in academic productiveness, as they traverse through the different stages in their teaching career. At present, there is a growing body of research that have widened our view relative to teachers' careers, which resulted to identification of career cycle consisting of phases or stages (Steffy, et al. 2000; Fessler and Christensen, 1992; Leithwood, 1992; Steffy, 1989). However, there is still a glaring gap in knowledge when it comes to understanding the relation between years of teaching in the context of the teachers teaching career cycle and academic productivity.

Models in teaching career cycle suggested that commensurate to passing through different stages over the course of their teaching career, it also connotes an increase number of years in teaching experience, and along with that, academic productiveness may change as well, of course controlling educational attainment since it has been shown that academic attainment is related to academic productiveness (The National Academies of Sciences, Engineering and Medicine, 2012). Given this, it makes sense to aver that the longer the years in teaching, characteristics of teachers changes as well relative to their professional priorities, concerns, instructional behaviors, understanding of students, awareness and understanding of the school and teaching environment, and perceptions of themselves, their work, and their professions (Lynn, 2002; Burden, 1982; Newman, Burden, and Applegate, 1980). As these changes occur, one of its possible effects is on academic productiveness, which may either increase or decrease.

\subsection{Objective of the Study}


With the above serving as backdrop, the aim of this research was to examine the relationship between academic productiveness and years of teaching of faculty and staff in higher education institution (HEI) through the lens of teaching career cycle model. From the findings, policy and professional development implications is presented particularly for faculty and staff in higher education institutions, in which the advancement and creation of new knowledge is significantly relevant. Thus, this made the study more compelling.

It must be noted that expert's definitions of teaching career cycle vary. However, one of the common denominator in which these definitions shared upon is that, it involved the number of years of teaching.

At this juncture, to gain an insight of the relationship between teaching career cycle and academic productiveness may inevitably have policy implications for the professional development as well as academic productiveness particularly of teachers in the higher education institutions. This implication could mean that not only the teachers themselves who need to be familiar with the notion of career cycle in order to assess themselves relative to academic productiveness, but, it is also incumbent upon school administrators to be able to appreciate an awareness of the said career cycle, and how this can impinge for the better the academic productivity of teachers (Leithwood, 1992) at the tertiary levels.

\subsection{The Problem}

In view of this, the study attempted to examine Huberman's teaching career cycle model in the context and setting of one of the State College in Northern Mindanao by way of attempting to demonstrate whether there is a relation between years of teaching and academic productivity.

More specifically, the aim of this study was to determine whether there is a discernible developmental progression in academic productiveness of tertiary teachers as their years of teaching increases - as viewed through the lens of Huberman's (1989a; 1989b; 1989c; 1992; 1993; 1995; 1996) teaching career cycle model. This model devotes itself to a detailed examination of current research on teacher's professional lives. In this model, Huberman gave an historical perspective to 
life-cycle research, and presented general trends particularly in regard to the phases teachers traverse in their career cycles.

Common sense dictates that from the teaching career perspective, teaching experience becomes richer and more refine as years of teaching increases, then, it follows that as teaching experience becomes richer and more refine, academic productiveness increase. In normal situation, the general trend is: academic productiveness increases as the teacher's years of teaching increases controlling for educational attainment. Therefore, deviation from this trend connotes an existing aberration in the normal course of the teacher's teaching career.

This observation is premised on what Huberman (1993: 195) averred that the teaching career cycle model is a process. As such, it implied that the sequential stages in teacher's teaching career cycle purported a process wherein teachers must pass through (Fessler, 1995: 187). Inherent in each stage in the career cycle is a major crisis that teachers must successfully overcome. Thus, this crisis can be interpreted as the aberration being referred in this study that inevitably occurs in the course of the teachers teaching career. This crisis though not explicitly spelled out have an impact to academic productivity whether for better or worse, which this study will attempt to gain an insight. Given this, it is therefore reasonable to construe that teachers who successfully transcend said crisis may manifest an increase academic productivity while those who are not successful may display decrease in academic productivity. From this perspective, it makes sense to aver that in Huberman's teaching career cycle model, low academic productivity of teachers is suggestive of a crisis being experienced, which have not yet been overcome or resolve, hence, this may imply of occurrence of aberration in the teachers teaching career cycle. We need to note that in Huberman's teaching career cycle model it consisted of the following stages, namely, career entry, stabilization, stocktaking, and serenity. However, it is the stage of stocktaking that Huberman (1989b) described as "problematic". This study attempted to show whether this assertion of Huberman had bearing in the context of Camiguin Polytechnic State College.

In view of this, the study attempted to demonstrate the veracity of the following propositions: If teacher's experience of crisis remains un-resolve in any stage in their teaching career cycle, then, their academic productiveness in that stage plummets. Hence, the trend in the overall academic productiveness in the teaching career cycle manifests not in a linear progressive fashion but 
punctuated with fluctuation depending in which stage in the teaching career cycle, teachers experienced a major crisis. Thus, if the stage of stocktaking is indeed "problematic", then, it follows that in the overall trend of teacher's academic productivity, this stage will show the deepest fluctuation vis-à-vis the rest of the stages. With this in mind, the following question was propounded: What is the overall pattern of academic productiveness of teachers in the tertiary level viewed from the perspective of Huberman's teaching career cycle?

\section{Methodology}

\subsection{Research Design}

The study utilized a survey design. A researcher's constructed survey questionnaire was used to gather data relative to demographic characteristics, namely, age, sex, years of service, employment status, educational attainment, and academic productiveness of faculty and staff.

\subsection{Locale of the Study}

The study was conducted in Camiguin Polytechnic State College situated in Barangay Balbagon, Mambajao, Camiguin in the Philippines during the Calendar Year 2019, which is a state-run higher education institution.

\subsection{Participants of the Study}

The respondents were the one-hundred thirty-five faculty and staff that includes but not limited to the Vice President for Academic Affairs, Research Development Director, Extension Director, Quality Assurance Coordinator, External ISA Assessor, administrators, deans, faculty members of the college and staff which have teaching responsibilities. A total enumeration of all the faculty and staff of CPSC was done, and they served as the study's respondents. For this, non-sampling errors were addressed and given especial attention during the collation and systematization of the collected data.

\subsection{Instrument Used}

The researcher's constructed questionnaire was subjected to three experts for face and content 
validity. Then, it was subjected to reliability test to thirty faculty and staff in one of the state college in the region of Northern Mindanao, in which the Province of Camiguin belongs. Cronbach Alpha $(0.86)$ was utilized in testing the reliability of the instrument.

The questionnaire has two main parts, namely, questions pertaining to the demographic characteristics of the respondents in terms of age, sex, years in service, educational attainment, and employment status, while the second part contain questions relative to academic productiveness, which is operationally defined as the number of books, educational manual, computer programs, papers published and presented, among others that relates to knowledge-intensive activities that contribute to a rapid pace of advancement in technical and scientific innovation.

Respondents were given the assurance that any information they will divulged relative to this study will be given utmost confidentiality and that there person is treated with anonymity. A consent form was crafted for this purpose.

\subsection{Treatment of Data and Statistical techniques for Data Analysis}

The data collected for age, years of service were ratio level data while data collected relative to educational attainment, academic productiveness, and employment status were nominal level data. Based on the study's definition of academic productiveness, faculty and staff were further classified into non-producers and producers. This classification is anchored on the operational definition of the study on academic productiveness wherein it refers to number of books, educational manual, computer programs, paper published and presented, among others of faculty and staff in which those that did not have even one of those aforesaid productions was classified as non-producers while those with at least one or more of those productions were classified as producers.

Descriptive statistics, namely, mean and standard deviation, were computed for ratio level data while for the nominal level data, the mode was ascertained. The data relative to years in service were categorized into four stages in accord with the stages or phases in the teaching career cycle model of Huberman. These are: career entry phase with corresponding years of service of one to three years; stabilization phase four to six years; stocktaking phase at mid-career, seven to eighteen years; and conservatism phase nineteen to thirty years of service and beyond. For purposes of description, a 
table of frequency and percentage distributions was created following the four phases of Huberman's teaching career cycle model. To facilitate analysis, cross-tabulation to generate frequency and percentage distributions was done between educational attainment and teaching career cycle and employment status. The Chi-square test of independence was applied to determine whether academic productiveness and teaching career cycle is associated and the relationship was then assessed of its effect size with the used of odds-ratio. This is in order to determine the odds of a particular phase in the teaching career cycle model in which faculty and staff's production of knowledge is being effected.

\section{Discussion of Results}

A total of one-hundred thirty-two faculty and staff served as respondents in this study. Thirty-five percent of which were holder of baccalaureate degree followed by thirty-three percent with master's degree, seventeen percent with master's units, eight percent have both doctorate degree and holder of doctoral units, respectively.

In the career entry phase, sixty-nine percent have baccalaureate degree compared to twenty-three percent with master's units, and eight percent with master's degree, and none with doctoral units and holder of doctorate degree. It is on this stage in which a great number of baccalaureate degree holder belonged. We need to note though that this stage is characterized by "exploration", "survival and discovery", and "reality shock".

On the other hand, as we move to stabilization phase, which is the next phase in the teachers teaching career cycle, baccalaureate degree holders decreases at thirty-eight percent which is now similar with those that have master's degree while the percentage of those with master's units likewise decrease to twenty-five percent, and no one with doctoral units and with doctorate degree belonged to this stage. In this stage, it must be underscored that such is characterized by "commitment", "independence", "emancipation", and "liberation" from a role of being a neophyte teacher. It is also in this stage wherein a feeling of security and of belongingness to a professional guild, as well as of personal commitment takes shape. It is on this stage therefore that school administrators should be attentive when it comes to identifying potential human resource for the institution. This is because it is the stage wherein personal commitment can be transformed in to an all-out commitment for the good of the College or the University. 
As we further move up in the stage of the teachers teaching career cycle, which is that of stocktaking phase, the number of baccalaureate degree holder slides to thirty-one percent which similar with that of those with master's degree at thirty-one percent while those with master's degree further decreases to twenty-one percent. In this stage, three percent have doctoral units as compared to 13 percent with a doctoral degree. This is the stage in the teacher's teaching career cycle model in which teacher's experienced "mid-life crisis". This is a stage in which distress is more pronounced and accentuated, which can be attributed to factors within the campus and in the family and homes.

Table 1. Frequency and Percentage Distributions of Faculty and Staff by Educational Attainment, Camiguin Polytechnic State College, CY 2019.

\begin{tabular}{|c|c|c|c|c|c|c|c|c|c|c|}
\hline \multirow{3}{*}{$\begin{array}{l}\text { Educational Attainment } \\
\text { of Faculty and Staff } \\
(\mathbf{N}=132)\end{array}$} & \multicolumn{8}{|c|}{ Teaching Career Cycle } & & \\
\hline & \multicolumn{2}{|c|}{$\begin{array}{l}\text { Career Entry } \\
\text { (1-3 yrs.) }\end{array}$} & \multicolumn{2}{|c|}{$\begin{array}{l}\text { Stabilization } \\
\text { (4-6 yrs.) }\end{array}$} & \multicolumn{2}{|c|}{$\begin{array}{c}\text { Stocktaking } \\
\text { (7-18 yrs.) }\end{array}$} & \multicolumn{2}{|c|}{$\begin{array}{l}\text { Serenity } \\
(19-30 \\
\text { yrs. })\end{array}$} & & \\
\hline & $\mathrm{F}$ & $\%$ & $\mathrm{~F}$ & $\%$ & $\mathrm{~F}$ & $\%$ & $\mathrm{~F}$ & $\%$ & & \\
\hline & & & $\begin{array}{l}1 \\
2\end{array}$ & & $\begin{array}{l}1 \\
0\end{array}$ & & 6 & & & $\begin{array}{c}34 . \\
8 \\
16 .\end{array}$ \\
\hline Baccalaureate & 18 & 69.23 & 8 & 37.5 & 7 & 31.25 & 1 & 14.29 & 46 & 7 \\
\hline With Master's Units & 6 & 23.08 & 1 & 25 & 1 & 21.875 & 1 & 2.38 & 22 & 32. \\
\hline Master & 2 & 7.692 & 2 & 37.5 & 0 & 31.25 & 9 & 45.24 & 43 & 6 \\
\hline With Doctoral Units & & 0 & & 0 & 1 & 3.125 & 9 & 21.43 & 10 & 7.6 \\
\hline Doctorate & & 0 & & 0 & 4 & 12.5 & 7 & 16.67 & 11 & 8.3 \\
\hline Total & 26 & 100 & $\begin{array}{l}3 \\
2\end{array}$ & 100 & $\begin{array}{l}3 \\
2\end{array}$ & 100 & $\begin{array}{l}4 \\
2\end{array}$ & 100 & 132 & 100 \\
\hline
\end{tabular}

Teachers in the stage of stocktaking commonly experienced themes of "uncertainty" or reassessment.

Such an experienced are common among those in their mid-career. This assessment period however has more to do with a decision to stay in one's job for the rest of one's life or to change before it is too late. This is characterized by waning job satisfaction, frustration, teacher "burnout" and disillusionment with teaching. Obviously, the academic productivity of teachers experiencing this mid-life crisis is directly or indirectly affected.

The last stage in the teachers teaching career cycle model is serenity. Supposedly, the ideal for an academic institution is that no baccalaureate degree holder should be in this stage. As expected, the percentage of those with baccalaureate degree further slides to fourteen percent, and the percentage with master's degree increases to forty-five percent while the number of those with master unit's 
decreases to two percent. Those with doctoral units increase to twenty-one percent and those with doctorate degree to seventeen percent.

Teachers in this stage are settling into a more relaxed and self-accepting activity in class, following periods of high energy and activism. The level of career ambition decreases, as does the level of investment, but the perception of confidence, effectiveness and serenity appears to compensate for this. However, seniority had brought with it benefits, and their goal was to preserve these privileges.

Given this profile of faculty and staff from the lens of the teachers teaching career cycle model, it was shown that the stage in which teachers are more productive is in the stage of serenity at seventysix percent followed by stabilization at fifty-three percent then that of stocktaking at forty-seven percent, and those with least academic production is Career Entry stage.

Table 2. Frequency and Percentage Distributions of Faculty and Staff by Academic Productiveness and by Stages in the Teachers Teaching Career Cycle

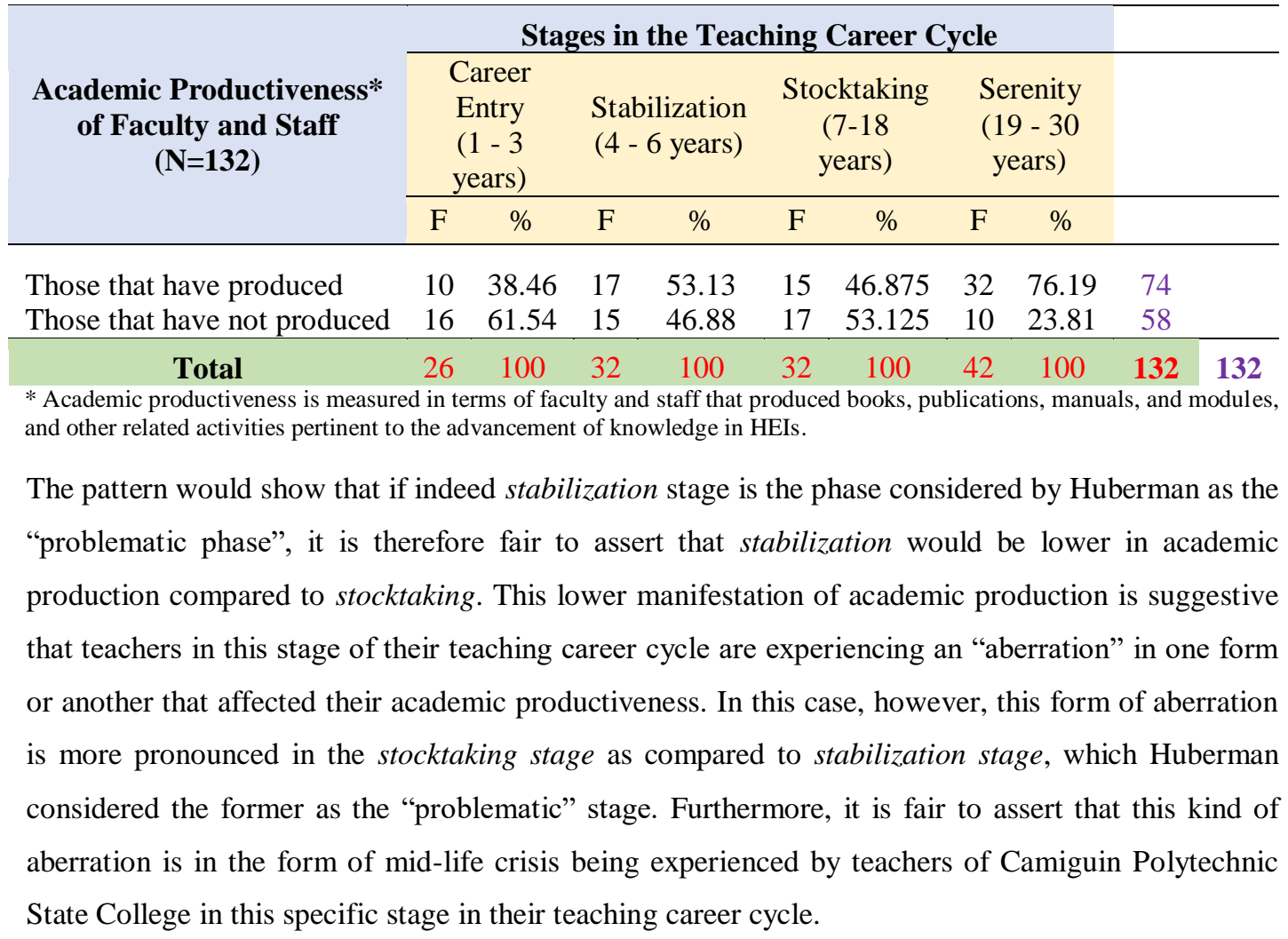


In addition, the association between stages in the teaching career cycle and academic productive is significant and is not due to random chance. As shown in the Chi-square Table below in which a Chi-square test of independence was performed to examine the relation between academic productiveness and stages in the teachers teaching career cycle. The relation between these variables was significant, $X^{2}(3, \mathrm{~N}=132)=11.39, p=.0098$. The findings disclosed that academic productiveness is significantly associated with the stages of the teachers teaching career cycle. In a word, such a relationship is not attributable to random chance rather in real life there is indeed an association between the two.

Table 3. Results

\begin{tabular}{|c|c|c|c|c|c|}
\hline & Career entry & Stabilization & Stocktaking & Serenity & Row Totals \\
\hline $\begin{array}{l}\text { Those that have } \\
\text { produced }\end{array}$ & $10(14.58)$ [1.44] & 17 (17.94) [0.05] & 15 (17.94) [0.48] 32 & $(23.55)$ [3.04] & 74 \\
\hline $\begin{array}{l}\text { Those that have } \\
\text { not produced }\end{array}$ & 16 (11.42) [1.83] & $15(14.06)[0.06]$ & $17(14.06)[0.61] 10$ & $(18.45)$ [3.87] & 58 \\
\hline Column Totals & 26 & 32 & 32 & 42 & $\begin{array}{l}\text { 132(Grand } \\
\text { Total) }\end{array}$ \\
\hline
\end{tabular}

Moving on, based on the result of the Chi-square test, a related measure of effect size was also derived which is that of odds ratio. The odds for a teacher who is at career entry stage to be academically productive is 10 to 16 or .625 that is sixty-three percent compared to the odds of teacher at the stabilization stage to be academically productive is 17 to 15 or 1.13 that is one hundred thirteen percent. In contrast, the odds for a teacher who is in the stocktaking stage to be academically productive is 15 to 17 or .882 that is eighty-eight percent while the odds of a teacher who is at the serenity stage to be academically productive is 32 to 10 or 3.2 that is 320 percent.

\section{Conclusion and Recommendations}

This study therefore would like to affirm to the finding of Huberman which somehow is in line with the finding in this study, in which the stocktaking stage is indeed a "problematic" stage. Even though the Huberman study was conducted in Switzerland - which is very different from the context of Camiguin Polytechnic State College in Northern Mindanao still his theoretical position that the stocktaking stage is indeed a problematic stage. 
However, it should be noted that the significant relationship between academic productiveness and teachers teaching career cycle notwithstanding the effect size of each stage in the teaching career cycle to academic productiveness is indicative for a need to come up with appropriate program interventions which should be done after the conduct of a mapping relative to tertiary faculty's teaching career cycle model. It is on this kind of mapping which this study had trail-blazed that an appropriate program intervention in enhancing academic productiveness can be conceptualized and then implemented.

What this study actually did is to pinpoint that this kind of approach in profiling faculty is a tool for administrators in the higher education institution to seriously take cognizance the importance of taking into account in their decision and policy making the relationship between academic productiveness and teaching career cycle model in the enhancement of their research and development activities as higher education institution.

\section{References}

Burden, P. (1982). Implications of teacher career development: New roles for teachers, administrators and professors. Action in Teacher Education 4(4): 21-25.

Fessler, R., and J. C. Christensen. 1992. The teacher career cycle: Understanding and guiding the professional development of teachers. Needham Heights, MA: Allyn and Bacon.

Fessler R. (1995). Dynamics of Teacher Career Stages. In Guskey T.R. and Huberman M. (Eds.). Professional Development in Education. Columbia University: Teachers College Press.

Floden R.E. and Huberman M. (1989). Teachers' Professional Lives: The State of the Art of Research on Teachers' Professional Lives. International Journal of Educational Research, 13 (4), pp. 455-466.

Fuller F. (1969). Concerns of Teachers: A Developmental Perspective. American Educational Research Journal, 6, pp. 207-226.

Huberman M. (Ed.). (1989a). Research on Teachers' Professional Lives. International Journal of Educational Research,13 (4). Pergamon Press, pp. 343-466.

Huberman M. (1989b). On Teachers' Careers: Once Over Lightly, with a Broad Brush. International Journal of Educational Research, 13 (4). Pergamon Press. Chapter 1, pp. 347-362.

Huberman M. (1989c). The Professional Life Cycle of Teachers. Teachers College Record, 91 (1), pp. 31-58.

Huberman M. (1992). Teacher Development and Instructional Mastery. In Hargreaves \& Fullan, Understanding Teacher Development. Cassell, London.

Huberman M. (1993). Steps Toward a Developmental Model of the Teaching Career. In Kremer-Hayon L.; Vonk H.C. and Fessler R. (Eds.). Teacher Professional Development: A Multiple Perspective Approach. Amsterdam/Lisse: Swets and Zeitlinger.

Huberman M. (1995). Professional Careers and Professional Development: Some Intersections. In Guskey T.R and Huberman M. (Eds.). Professional Development in Education. Columbia University: Teachers College Press.

Huberman M. (1996). Focus on Research Moving Mainstream: Taking a Closer Look at Teacher Research. 
Language Arts, 73, (2), pp. 124-140.

Leithwood, K. A. 1992. The principal's role in teacher development. In Teacher development and educational change, ed. M. Fullan and A. Hargreaves, 86-103. Bristol, PA: Falmer.

Lynn, S. K. (2002). The Winding Path: Understanding the Career Cycle of Teachers. The Clearing House, 179-182.

Macha, W., Mackie, C., \& Magaziner, J. (2018, May 25). Outcomes in Higher Education in the Philippines. Retrieved from Knowledge Analysts at WES: https://wenr.wes.org/2018/03/education-in-the-philippines.

Newman, K.; Burden, P.; and Applegate, J.. 1980. Helping teachers examine their long-range development. Paper presented at the annual conference of the Association of Teacher Educators, Washington, D.C.

Steffy, B. E. 1989. Career stages of classroom teachers. Lancaster, PA: Technomic.

Steffy, B. E., M. P. Wolfe, S. H. Pasch, and B. J. Enz. 2000. Life cycle of the career teacher. Thousand Oaks, CA: Corwin.

The National Academies of Sciences, Engineering and Medicine. (2012). Improving Measurement of Productivity in Higher Education (2012). Retrieved from The National Academy Press: https://www.nap.edu/read/13417/chapter/5\#59

Wittrock M. (Ed.). (1986). Handbook of Research on Teaching. (Third Edition). New York: Macmillan. 